\title{
Pathology of valved venous homografts used as right ventricle-to-pulmonary artery conduits in congenital heart disease surgery
}

\author{
Chrystalle Katte Carreon, MD, ${ }^{\text {,ee }}$ Annachiara Benini, MD, ${ }^{\mathrm{b}, \mathrm{f}}$ Christopher Baird, MD, ${ }^{\mathrm{c}, \mathrm{g}}$ \\ David Hoganson, MD, ${ }^{c, g}$ Michele Borisuk, RN, MSN, ${ }^{c, g}$ Sitaram Emani, MD, ${ }^{c, g}$ \\ Sophie Hofferberth, MBBS, ${ }^{c, g}$ Robert F. Padera, Jr, MD, PhD, ${ }^{\text {d,e }}$ and Stephen P. Sanders, MD ${ }^{\mathrm{a}, \mathrm{b}, \mathrm{c}, \mathrm{f}}$
}

\section{ABSTRACT}

Objectives: Although valved venous homografts (VVHs) are used for establishing right ventricle-to-pulmonary artery continuity in some complex heart defects, the tissue changes that occur in situ have not been described. We review the gross and microscopic changes observed in explanted VVH conduits and their effects on functionality.

Methods: In total, 20 explanted VVH conduits were evaluated for valve integrity, presence of thrombus, and stenosis. Hematoxylin and eosin- and trichromestained sections were reviewed for neointima formation, wall remodeling, inflammation, and calcification. Regurgitation and narrowing were assessed on pre-explant echocardiogram, and angiographic video clips were correlated with tissue findings. The source of the proliferating cells within the conduits was investigated by fluorescent in situ hybridization.

Results: Thirteen male and 7 female infants underwent VVH implantation either as part of a composite Sano shunt $(65 \%)$ or to establish right ventricle-topulmonary artery continuity in biventricular hearts $(35 \%)$. The median duration of conduits in situ was 140 days (range: 98-340 days). Conduits were predominantly explanted for staged conversion to bidirectional Glenn (60\%) and conduit upsizing $(20 \%)$. The valves remained intact and functional in $75 \%$ of cases. Occlusive thrombosis was absent in all. Wall thickening due to neointima formation and wall remodeling was uniformly present and appeared to be driven by smooth muscle actin-expressing cells, which by fluorescent in situ hybridization are predominantly of recipient origin. Minimal calcification and mild adventitial chronic inflammation were present.

Conclusions: Vein wall thickening is a uniform finding and can cause stenosis. The valves remain functional in most, and vein walls undergo remodeling with only minimal inflammation and calcification. (J Thorac Cardiovasc Surg 2019;157:342-50)

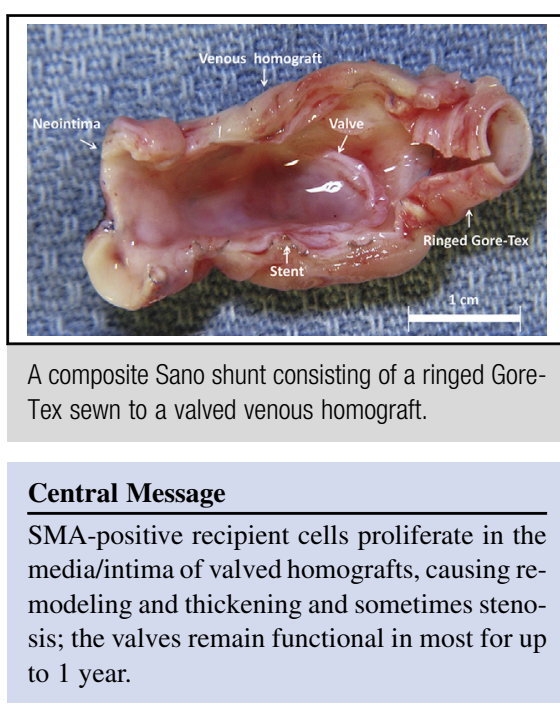

\section{Perspective}

Valved venous homografts offer several advantages for use in neonates and small infants, including excellent handling and hemostatic characteristics, availability, and lower cost. Our study confirms that although wall remodeling and thickening occur in all, venous homografts are suitable for short- or medium-term use in this population.

See Editorial Commentary page 351.
From the Departments of ${ }^{\mathrm{a}}$ Pathology, ${ }^{\mathrm{b}}$ Cardiology, and ${ }^{\mathrm{c}}$ Cardiac Surgery, Boston Children's Hospital, Boston; 'Department of Pathology, Brigham and Women's Hospital, Boston; and Departments of ${ }^{\mathrm{e}}$ Pathology, ${ }^{\mathrm{f}}$ Pediatrics, and ${ }^{\mathrm{g}}$ Surgery, Harvard Medical School, Boston, Mass.

Received for publication June 14, 2018; revisions received Aug 22, 2018; accepted for publication Aug 26, 2018; available ahead of print Nov 7, 2018.

Address for reprints: Stephen P. Sanders, MD, Department of Pathology, Boston Children's Hospital, Mail Code BCH 3027, 300 Longwood Ave, Boston, MA 02115 (E-mail: stephen.sanders@childrens.harvard.edu).

0022-5223/\$36.00

Copyright (c) 2018 by The American Association for Thoracic Surgery

https://doi.org/10.1016/j.jtcvs.2018.08.102
Establishment of a right ventricle (RV) to pulmonary artery (PA) pathway is an integral part of surgical repair or palliation of several common congenital heart defects. ${ }^{1-6}$

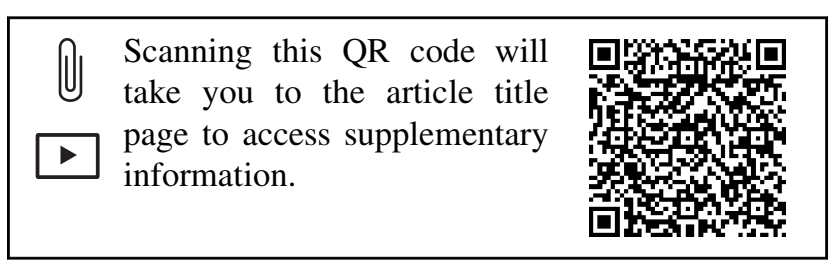




\author{
Abbreviations and Acronyms \\ FISH $=$ fluorescent in situ hybridization \\ $\mathrm{FVH}=$ femoral vein homograft \\ $\mathrm{PA}=$ pulmonary artery \\ $\mathrm{RV}=$ right ventricle \\ $\mathrm{SMA}=$ smooth muscle actin \\ $\mathrm{SVH}=$ saphenous vein homograft \\ $\mathrm{VVH}=$ valved venous homograft
}

Nonetheless, the ideal RV-to-PA conduit-one that is nonthrombogenic, exhibits long-term patency, is readily available in a range of sizes, has excellent handling characteristics, long-term valve function, potential for growth, low risk of infection, and is inexpensive-has yet to be developed. ${ }^{6-8}$

Cryopreserved valved venous homografts (VVHs), either femoral or saphenous, are being used at select institutions for establishing RV-to-PA continuity. ${ }^{6}$ VVHs are readily available in a variety of sizes and contain 2 to 4 competent valves. Consequently, a valved segment of the desired size for use in neonates and infants is almost always obtainable. Moreover, the thin vein wall has excellent sewing and hemostatic characteristics for anastomosis to neonatal and infant PAs. The graft can also be directly anastomosed to a right ventricular incision without a hood or by using an intervening ringed Gore-Tex graft. VVHs have been associated with less calcification in comparison with valved pulmonary and aortic homografts and are generally less expensive. Recent reports support the clinical utility of VVHs and have highlighted improved interstage PA growth. ${ }^{9-11}$

Despite the increased use of VVHs at our center and some others, minimal attention has been given to the gross and microscopic tissue changes that occur in these conduits in situ and how these relate to overall clinical performance. The objective of our study is to describe the gross and microscopic findings in explanted VVHs and to relate these to functionality.

\section{METHODS \\ Subjects}

Patients were identified through a search of the Cardiac Surgery and Pathology databases of Boston Children's Hospital from September 2014 to July 2017. Patients were included if they had undergone cardiac surgery in which a VVH, either a femoral vein homograft $(\mathrm{FVH})$ or saphenous vein homograft $(\mathrm{SVH})$, was used to create RV-to-PA continuity and the conduit was afterward explanted at a later surgery or at autopsy. Patients were excluded if a stent had been placed within the venous homograft segment of the conduit. This study was approved by the institutional review board (no. CR00024083).

\section{Clinical Data}

A retrospective comprehensive review of electronic medical records, operative notes, imaging studies (echocardiography and angiography), and pathology reports was performed. The following patient demographic data were obtained: sex, height, weight, body surface area, and age at the time of conduit placement and explantation. The clinical data included cardiac diagnoses, type and size of homograft, duration of conduit in situ, intervening procedures and indication, reason for explantation, and use of an external, confining stent. The pre-explant echocardiogram and angiographic video clips were reviewed for evidence of conduit regurgitation and luminal narrowing.

\section{Surgery}

The cryopreserved valves were supplied by CryoLife and LifeNet. The VVHs were a section of cryopreserved SVH or FVH (CryoLife, Inc, Kennesaw, Ga; LifeNet, Virginia Beach, Va). Personal communication from the commercial provider of the CryoLife VVH states that all VVHs used in this study were from male donors. Generally, after distending the VVH with saline, a single valve was sectioned from the donor segment and the valve was stored in saline until implanted.

When used as part of a Sano shunt, the VVH segment was sutured to a 5or 6-mm diameter by $20-\mathrm{mm}$ long ringed PTFE tube, which was then inserted into the RV through a stab incision in the anterior infundibular wall. ${ }^{12}$ When used to establish RV-to-PA continuity in biventricular hearts, the vein graft was beveled and sewn directly to the epicardial surface of the $\mathrm{RV}$ around an orifice created by excision of anterior infundibular wall muscle. In both cases, the distal end of the vein graft was sewn directly to the native or unifocalized PAs. In some cases, the valved portion of the vein graft was enshrouded with an external $8 \times 15$-mm biliary stent (Cordis, Tipperary, Ireland) and predilated to 6 to $8 \mathrm{~mm}$ in diameter to prevent dilation of the valved portion and incompetence of the valve. At explantation, the VVH was dissected free of surrounding tissue, separated from the PA and RV (including a segment of ringed PTFE if used), and submitted for pathological examination.

\section{Pathology}

The specimens were examined grossly and photographed on receipt. The vein graft was opened longitudinally; special attention was given to valve integrity, presence of thrombus, and luminal narrowing from grossly visible calcification and/or venous wall thickening. A full-length longitudinal section was obtained for histology. In some cases, a transverse section was also obtained. The sections were then fixed in $10 \%$ buffered formalin, embedded in paraffin, and sectioned into $5-\mu \mathrm{m}$-thick ribbons for subsequent staining. Sections were mounted and stained with hematoxylin and eosin, Masson's trichrome, and Miller's elastic stains.

Three samples from unused portions of unimplanted femoral VVH were processed as described previously for comparison. Before processing, the samples were fixed in $10 \%$ buffered formalin under mild distending pressure both without and with a 6-mm external confining tube to simulate VVH segments that had been implanted with a confining external stent.

Immunohistochemical staining was used to identify endothelial cells (CD 31) and smooth muscle cells/myofibroblasts (smooth muscle actin [SMA]). Paraffin fluorescent in situ hybridization (FISH) was used to determine the sex of individual cells in paraffin-embedded sections from $5 \mathrm{sam}$ ples of VVH: 1 unimplanted segment, $1 \mathrm{VVH}$ explanted from a male recipient, and $3 \mathrm{VVHs}$ explanted from a female recipient. A dual-color FISH probe set (Abbott Molecular, Abbott Laboratories. Abbott Park, Ill), CEPY (a SatIII probe, labeled with SpectrumGreen) directed at Yq12 and CEPX (an alpha-satellite probe, labeled with SpectrumOrange) directed at Xp11.1-q11.1, was hybridized to formalin-fixed, paraffinembedded sections. Fifty cells were counted from each sample to determine the sex distribution of cells in the sample: $\mathrm{XY}$ or $\mathrm{Y}=$ male; $\mathrm{XX}=$ female $\mathrm{X}=$ indeterminate.

The extent of inflammation, neointima formation, vein wall remodeling, and calcification was graded semiquantitatively (none, minimal, mild, moderate, severe) by an experienced cardiac pathologist (R.F.P.). Descriptive statistics were used to characterize patient demographic information and observed gross and microscopic features. 


\section{RESULTS \\ Clinical}

During the study period, 20 consecutive VVHs used for establishing an RV-to-PA connection and meeting the aforementioned criteria were explanted. Eleven patients $(65 \%)$ were male. The median age at implantation was 5 days (range: 1-147 days) and the median weight was $3.2 \mathrm{~kg}$ (range: $2.1-5.14 \mathrm{~kg}$ ). Ten FVHs and 3 SVHs were implanted as part of a composite Sano shunt $(\mathrm{n}=13,65 \%)$ for Norwood stage I palliation (Figure 1), and $4 \mathrm{FVH}$ and $3 \mathrm{SVH}$ were used to establish RV-to-PA continuity $(\mathrm{n}=7,35 \%)$ in biventricular hearts (Figure E1). Moreover, 17 (85\%) of the VVH were implanted as a component of a composite conduit, which included a segment of ring-reinforced PTFE, whereas $3(15 \%)$ were implanted without the PTFE segment. Hypoplastic left heart syndrome comprised $50 \%$ of the patient population, followed by double-outlet $\mathrm{RV}(\mathrm{n}=3 ; 15 \%), 2$ of which were associated with heterotaxy syndrome, and tetralogy of Fallot $(\mathrm{n}=3 ; 15 \%)$. Truncus arteriosus, transposition of great arteries, and critical aortic stenosis were also represented. An external, predilated stent was used in 8 patients ( 6 composite Sano shunts, 2 RV-to-PA conduits). One patient had undergone external stent placement around the Sano shunt 10 days after implantation.

The median duration of conduits in situ was 140 days (range: 98-340 days), and the conduits were explanted at a median age of 4.8 months (range: 3.5-16.2 months) and

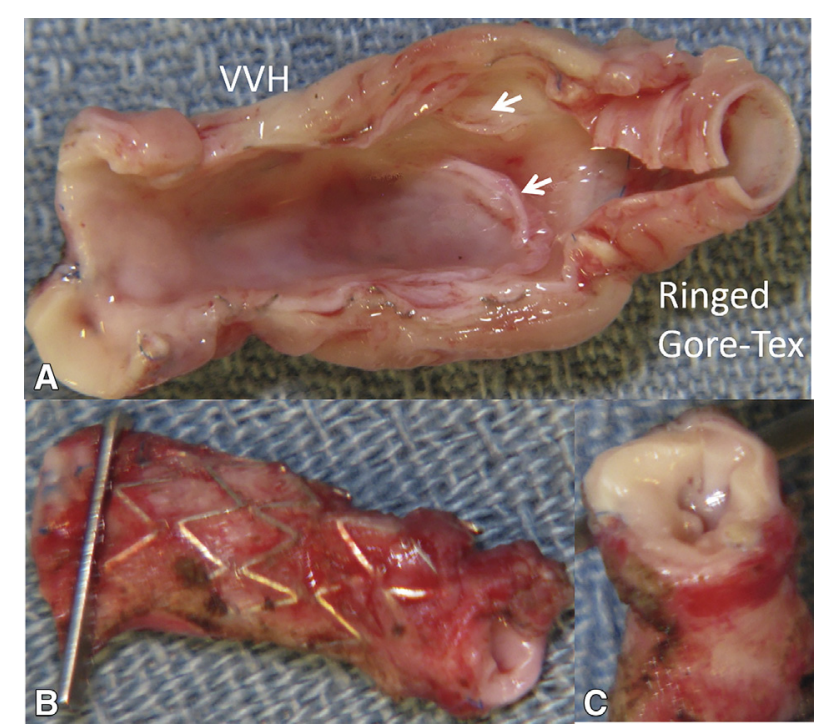

FIGURE 1. Composite Sano shunt (A) consisting of a piece of ringed PTFE sewn to a femoral VVH enclosed in a confining, external stent (B). Note the intact venous valve (arrows) and mild neo-intima formation. The graft is covered externally by a layer of vascularized fibrous tissue. An end-on view (C) shows the irregular wall thickening due to fibrointimal and medial hyperplasia. The graft was in situ for 125 days. $V V H$, Valved venous homograft. median weight of $5.8 \mathrm{~kg}$ (range: $4.1-10.7 \mathrm{~kg}$ ). Conduit explantation was performed for staged conversion to bidirectional Glenn $(\mathrm{n}=12 ; 60 \%)$, conduit upsizing $(\mathrm{n}=4$, $20 \%)$, conversion to aortopulmonary shunt $(\mathrm{n}=2,10 \%)$, stenosis at the distal anastomosis $(\mathrm{n}=1,5 \%)$, and anastomotic pseudoaneurysm $(n=1,5 \%)$. Five patients with a Sano shunt underwent balloon dilation and/or stenting of the PTFE portion of the composite shunt. One patient had a stent placed in the VVH and was excluded from the study according to selection criteria. One patient underwent conversion of a Sano shunt to a modified Blalock-Taussig shunt. In 2 of 7 patients with potentially biventricular hearts, the VVH was explanted during reintervention for pulmonary vein stenosis or anastomotic pseudoaneurysm. In 2 others, a Glenn anastomosis was created because the patient was not able to undergo completion of 2-ventricle repair at that time. The other 3 had the VVH in place for 200 to 400 days, during which the patient doubled or tripled weight.

\section{Functional}

Review of pre-explant echocardiograms revealed the absence of regurgitation in most of the patients $(n=13$; $65 \%$ ) (Video 1) and mild-to-moderate regurgitation in the remaining 7 patients (35\%) (Video 2). Regurgitation tended to be more frequent among female recipients $(43 \%$ vs $23 \%)$ and among those without an external stent ( $45 \%$ vs $22 \%$ ).

No luminal narrowing was appreciated in 10 patients $(50 \%)$ by angiography. The severity and site of stenosis varied in the 10 affected grafts: 6 mild (distal $=2$, diffuse $=4$ ), 3 moderate (at anastomosis $=1$, proximal $=1$, proximal and distal $=1$ ), and 1 moderate-to-severe stenosis (diffuse) (Figure 2). Early-on partial kinking of the graft was occasionally noted due to excessive length, which led to

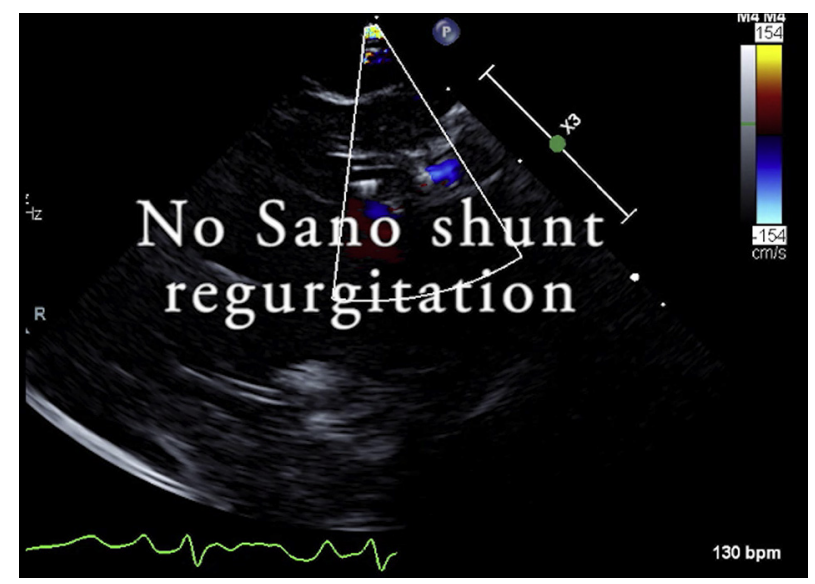

VIDEO 1. Review of pre-explant echocardiograms revealed absence of regurgitation in most of the patients $(\mathrm{n}=13 ; 65 \%)$. Video available at: https://www.jtcvs.org/article/S0022-5223(18)32497-8/fulltext. 


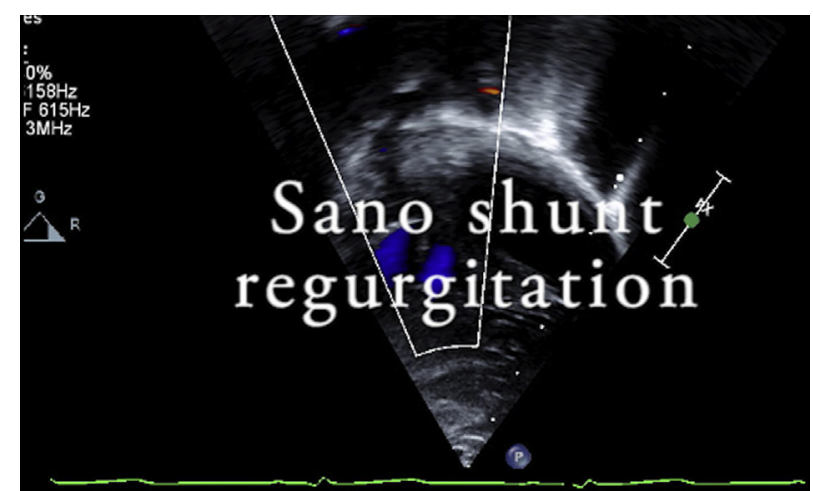

VIDEO 2. Review of pre-explant echocardiograms revealed mild-tomoderate regurgitation in the remaining 7 patients $(35 \%)$. Video available at: https://www.jtcvs.org/article/S0022-5223(18)32497-8/fulltext.

modification of our technique. Stenosis was almost twice as frequent among female recipients (71\% vs $38 \%)$. In addition, $63 \%$ of stented and $42 \%$ of nonstented VVH developed some degree of stenosis. Although it appears that in our cohort the conduits with external stents had more severe stenosis overall, the difference is not significant, and we did not note any histologic differences.

\section{Pathology}

The explanted vein grafts were covered with varying amounts of fibrous tissue (Figure 1) on their adventitial aspects. All 20 specimens showed thickened vein walls (Figure 1,C) when compared with a sample of unimplanted vein graft (Figure 3) secondary to a white glistening and smooth fibrous layer (neointima formation) that lined the entire lumen of the conduit including both the VVH and PTFE segments (Figure 1, A). A venous valve was identified and was intact in 15 specimens $(75 \%)$, thickened in 2 $(10 \%)$, possibly fused onto the wall in $2(10 \%)$ with visible

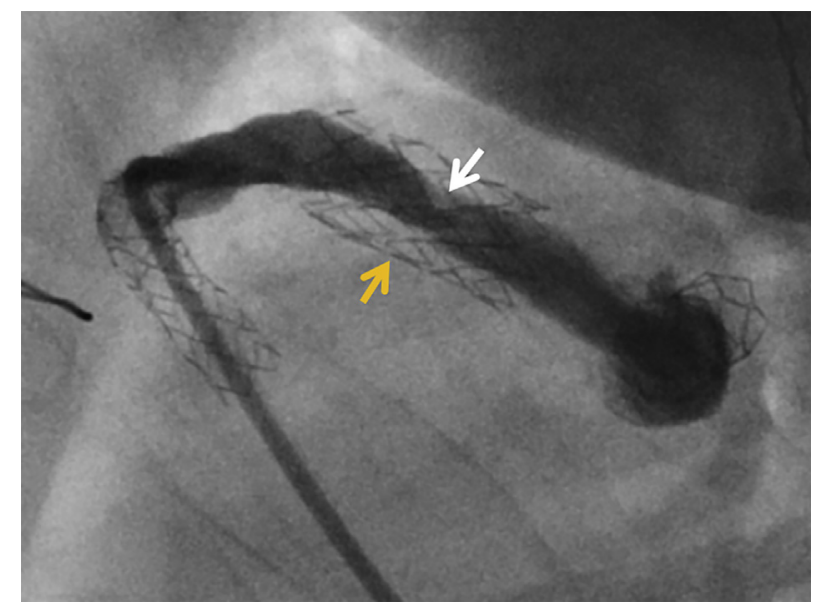

FIGURE 2. Discrete, mid-segment narrowing in the VVH (white arrow). The VVH is within an external stent (yellow arrow). Note the diffuse thickening of the wall between the external stent and the contrast-filled lumen. lines of valve attachment to the vein wall, and present but disrupted secondary to procurement for microbiologic cultures in $1(5 \%)$. No grossly apparent thrombosis or calcification was present in any specimen.

Microscopically, varying degrees of adventitial neovascularization and fibrosis (Figure E2) were present. Variable, but no more than moderate, (none -6 , minimal -7 , mild -6 , moderate -1 ) inflammatory cell infiltrate consisting predominantly of lymphocytes, plasma cells, and scattered macrophages was observed in the adventitia; 2 specimens showed scattered eosinophils as well (Figure E2). The average adventitial inflammation score was lower for female recipients (0.29 vs 1.46). All specimens exhibited mild $(n=9)$ or moderate $(n=11)$ venous graft wall remodeling and thickening characterized by fibrointimal proliferation consisting of SMA-positive spindle cells, likely representing proliferating myofibroblasts and/or smooth muscle cells, with deposition of extracellular matrix (Figure 4). The luminal surface was mostly but not completely covered by regrown endothelium, as confirmed by CD31 immunostaining (Figure 4).

SMA-positive spindle cells similar to those within the proliferating intimal layer were also noted in the media along with disruption of medial smooth muscle and deposition of collagen (Figure 5). Microthrombus was noted covering the luminal surface of areas denuded of endothelium and in the sinuses of the venous valves in 5 specimens (Figure E3). The venous valves were relatively thin and without significant fibrosis, calcification (Figure 6), or inflammation, although mild fibrointimal proliferation was noted at the base of some. Moreover, we noted that fibrointimal proliferation was patchy in some cases, resulting in uneven wall thickening (Figure E4). Adventitial calcification (minimal in 1 specimen, mild in 4, and moderate in 4) was present in less than half of the specimens $(\mathrm{n}=9,45 \%)$ and was mostly along suture lines; histiocytes with foreign body giant cell formation were also identified adjacent to suture material (Figure E5). The grafts were entirely viable with no evidence of necrosis. We did not observe histologic differences between patients with a Sano shunt and those with biventricular hearts, but the numbers are small.

The 3 unimplanted VVH samples had the appearance of a normal vein with a thin wall, gray-white, smooth adventitial surface and a smooth yellow-white luminal surface. Microscopic examination showed few if any identifiable endothelial cells, a tunica media with preserved smooth muscle cells, and an adventitia with dense collagen and minimal vascularization (Figure 3). Some of the endothelial and smooth muscle cells appear quite pyknotic. There were scattered lymphocytes mostly in the adventitia.

All 5 samples tested were successfully hybridized by FISH. The unimplanted VVH showed one $X$ hybridization signal and one $\mathrm{Y}$ hybridization signal consistent with one 

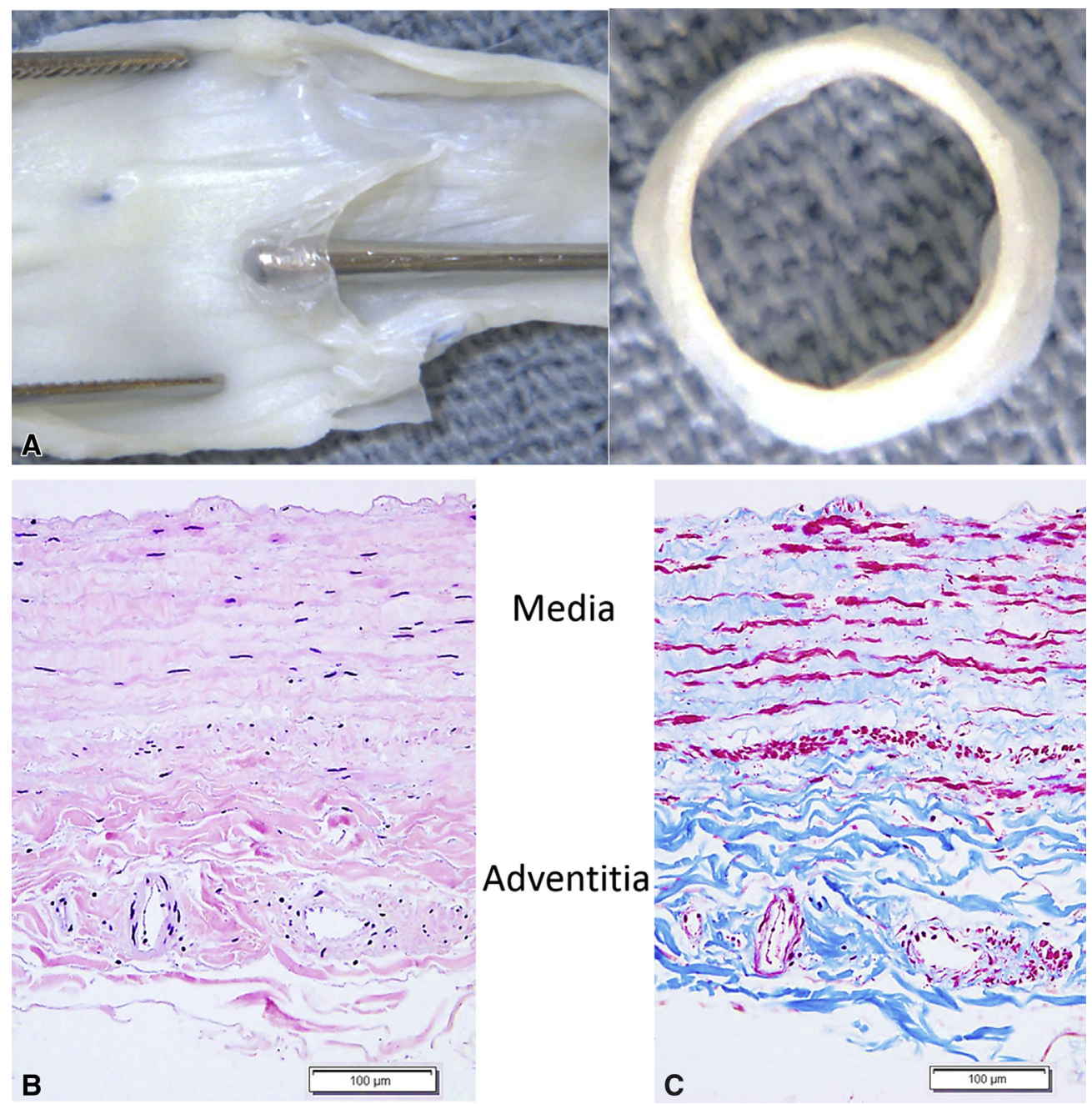

FIGURE 3. Unimplanted valved venous homografts. (A) Longitudinal section showing valve leaflet (left) and cross-section showing the thin vein wall. (B) Hematoxylin and eosin and (C) Trichrome, 20×, showing no clear endothelial layer, a laminar medial layer with smooth muscle, collagen fibers and fibroblasts in orderly distribution, and an uninflamed adventitial layer with dense collagen and small vessels.

copy of the X chromosome and one copy of the Y chromosome (male sex chromosome constitution) (Figure 7, $A$ ) in all cells examined; the same results were observed in the VVH explanted from a male recipient. One of the female recipients demonstrated $2 \mathrm{X}$ hybridization signals in the majority of cells consistent with 2 copies of the $\mathrm{X}$ chromosome (female sex chromosome constitution) and $1 \mathrm{X}$ hybridization signal and $1 \mathrm{Y}$ hybridization signal consistent with 1 copy of the $\mathrm{X}$ chromosome and 1 copy of the Y chromosome (male sex chromosome constitution) in a minor population $(\mathrm{n}=8 / 50 ; 16 \%)$ of cells (Figure $7, B$ and $C$ ). The VVH from the 2 other female recipients showed $2 \mathrm{X}$ hybridization signals and no $\mathrm{Y}$ hybridization signals consistent with 2 copies of the $\mathrm{X}$ chromosome (female sex chromosome constitution). FISH signals were detected in the proliferating spindle cells within the myo-intimal region.

Interestingly, marked wall remodeling was present in the 2 cases without identifiable residual donor male cells when compared with the specimen with occasional residual male cells. The inflammation in the $3 \mathrm{VVH}$ explanted from female recipients was minimal. One of the female VVH recipients without identifiable residual male cells also had the longest duration (387 days) of graft in situ.

\section{DISCUSSION}

Our review of explanted VVH revealed the following: (1) uniform myo-intimal remodeling with thickening of the vein wall in all cases and associated with angiographic evidence of luminal narrowing in about half of cases; (2) minimal inflammatory response; (3) minimal calcification, mostly associated with the external stent or suture material and foreign body reaction; and (4) preserved valve anatomy in $75 \%$ and function in $65 \%$ of cases. The VVH has not resulted in more reinterventions compared with the standard nonvalved polytetrafluoroethylene in the patients treated to date. ${ }^{13}$ The external stent 

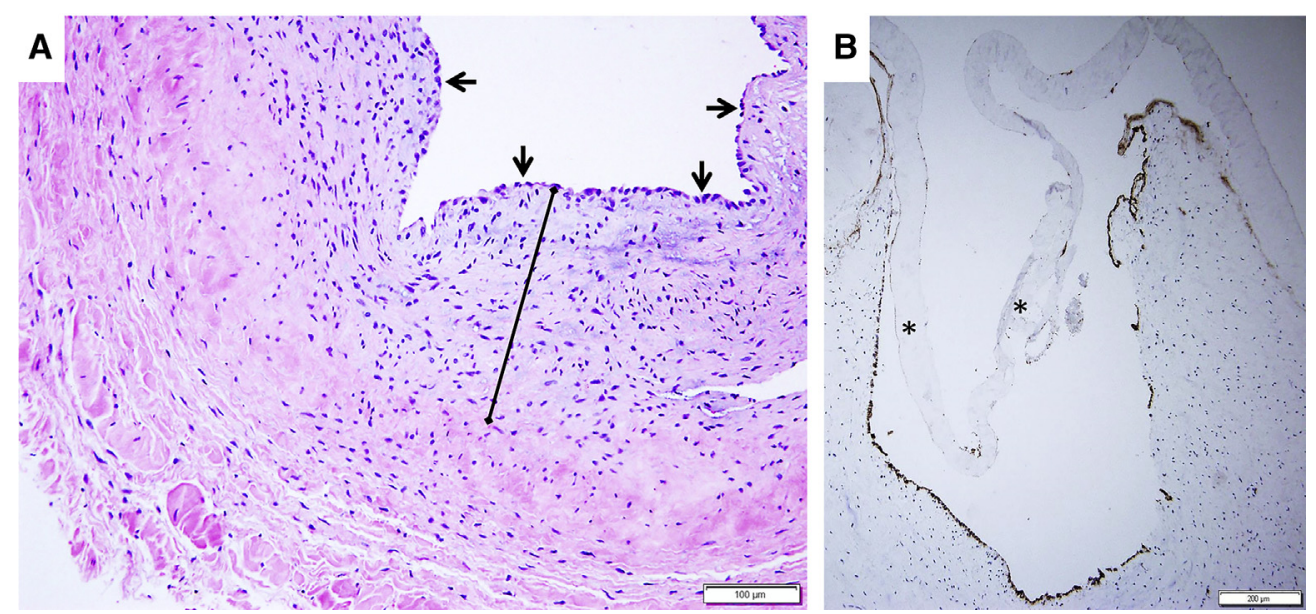

FIGURE 4. (A) Fibrointimal hyperplasia (bar) of varying thickness, mostly covered by regrown endothelium (arrows), was noted in all explanted valved venous homografts. (hematoxylin and eosin, 20×) (B) Immunostain for CD31 (brown) confirming the presence of endothelial cells on most of the luminal surface but not on the venous valve $\left(^{*}\right)(10 \times)$.

has an unclear impact related to valve function and stenosis of the graft, although we continue to gather data and will learn more with further clinical experience. The composite grafts are not more difficult to excise; the vein portion separates easily from adjacent tissue and can be trimmed and oversewn without additional patching of the PA. The VVH continues to be used for establishing RV-PA continuity at our center.
The clinical utility and acceptability of VVH for establishing RV-PA continuity has been demonstrated in previous reports. ${ }^{8-11}$ We have concentrated on the gross and histologic findings in explanted grafts and the relationship of our findings to clinical performance. First, we found remodeling and thickening of the $\mathrm{VVH}$ wall in all cases examined. Fibrointimal hyperplasia with uniform or focal thickening of the intimal layer was seen in all grafts. The

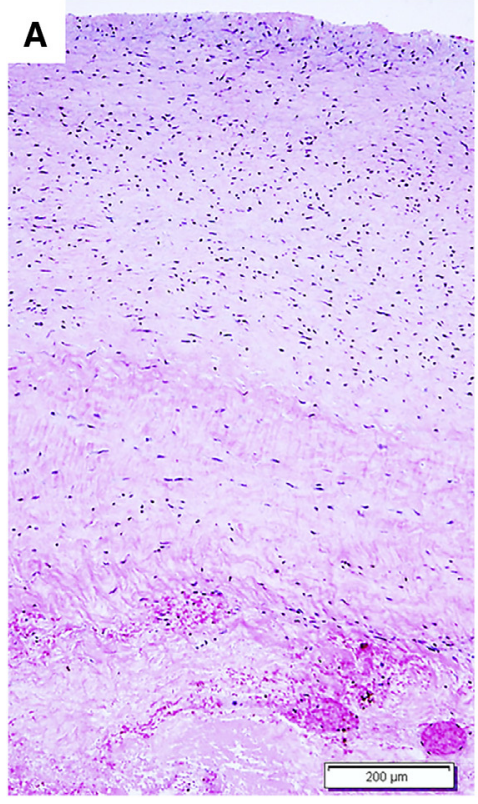

\section{Fibrointimal hyperplasia}

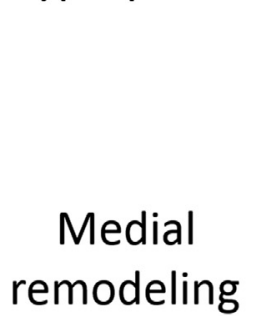

Adventitia
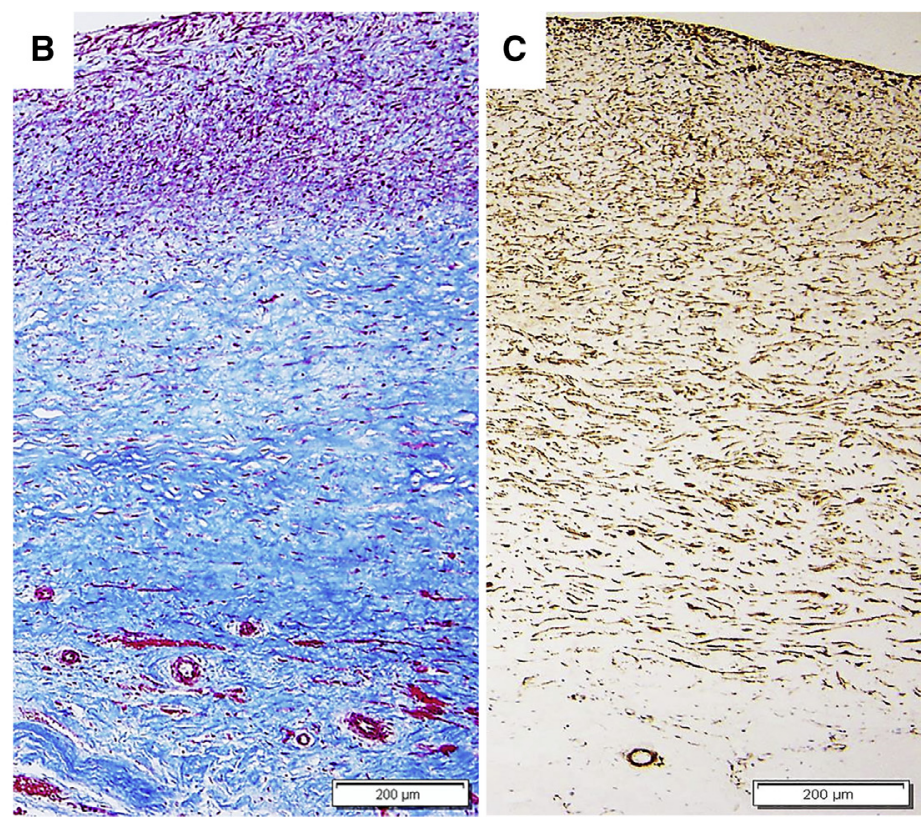

FIGURE 5. Femoral vein homograft explanted after 96 days (A, hematoxylin and eosin; B, Trichrome; C, SMA immunostain, 10×) showing vascularized fibrous tissue covering the residual vein adventitia (bottom), partially remodeled media with disruption of smooth muscle, and a thick neo-intima (top). Thickening of the medial layer is also a common feature (trichrome stain). When compared with the unimplanted homograft (Figure 4), the laminar architecture of smooth muscle within the medial layer has been disrupted by infiltrating SMA-expressing cells (likely myofibroblasts) highlighted by immunostain for SMA (C), similar to the cells comprising the proliferating fibrointimal layer, which results in overall thickening of the wall. SMA, Smooth muscle actin. 


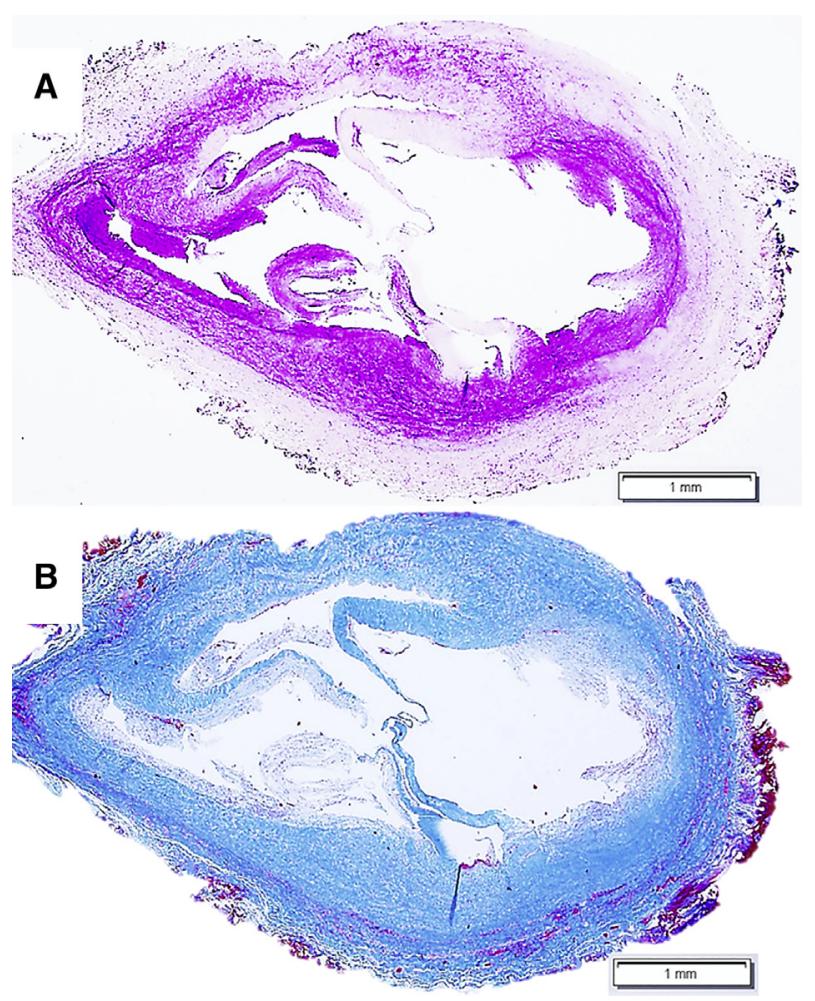

FIGURE 6. Femoral vein homograft explanted after 140 days (A, hematoxylin and eosin; $\mathrm{B}$, Trichrome, $2 \times$ ) showing intact venous valve with mild neointima formation at the base of the leaflets.

dominant cell type in the thickened wall is a myofibroblast or smooth muscle cell, observed mostly in the thickened intimal layer but also in the media. The donor smooth muscle in the media was largely replaced with collagen and recipient-derived SMA-expressing cells. The observed wall thickening is the substrate for much, if not most, of the narrowing of grafts observed clinically and that prompted intervention. ${ }^{8,9}$ This process seems analogous to changes described in saphenous vein grafts used for coronary artery bypass. ${ }^{14} \mathrm{~A}$ thin microthrombus layer covered small patches of denuded luminal surface in about a quarter of cases, the organization of which might have contributed to the intimal thickening as well. Sex chromosome analysis demonstrated that the great majority of proliferating SMAexpressing cells in the thickened vessel wall are of recipient origin. In only 1 case examined were residual donor cells detected. The explanted VVH with no identifiable residual donor cells had been in situ longer ( 1 for 387 days) than the chimeric one, suggesting gradual replacement of donor cells by proliferating recipient cells.

We demonstrated the presence of background VVH male donor cells and more numerous proliferating female recipient cells within the graft implanted in one of the female recipients, consistent with "tissue chimerism," a phenomenon previously described by Koolbergen and colleagues ${ }^{15,16}$ in at least $60 \%$ of their homograft valve explant specimens. Previous studies have also described the survival of donor cells in the graft, ${ }^{17}$ whereas other studies claimed that the cellular constituents are mainly from ingrowth of recipient cells. $^{18,19}$ Our own findings confirm that both donor and recipient cells can be detected in the same homograft. Whether the recipient cells predominate over time by proliferation with subsequent elimination of pre-existing donor cells is unclear but would be consistent with our data. Similarly, only recipient cells were identified in the $30 \%$ of the cases in the series by Koolbergen and colleagues. ${ }^{15}$ Performing FISH analysis on a larger cohort may generate more conclusive data on the possible factors that contribute to the eventual disappearance of the donor cells in a subset of these grafts.

We did not observe grossly evident thrombosis in any graft. This diminished thrombogenicity had been previously attributed to the presence of potentially functional lining endothelium. We did note endothelial coverage of most of
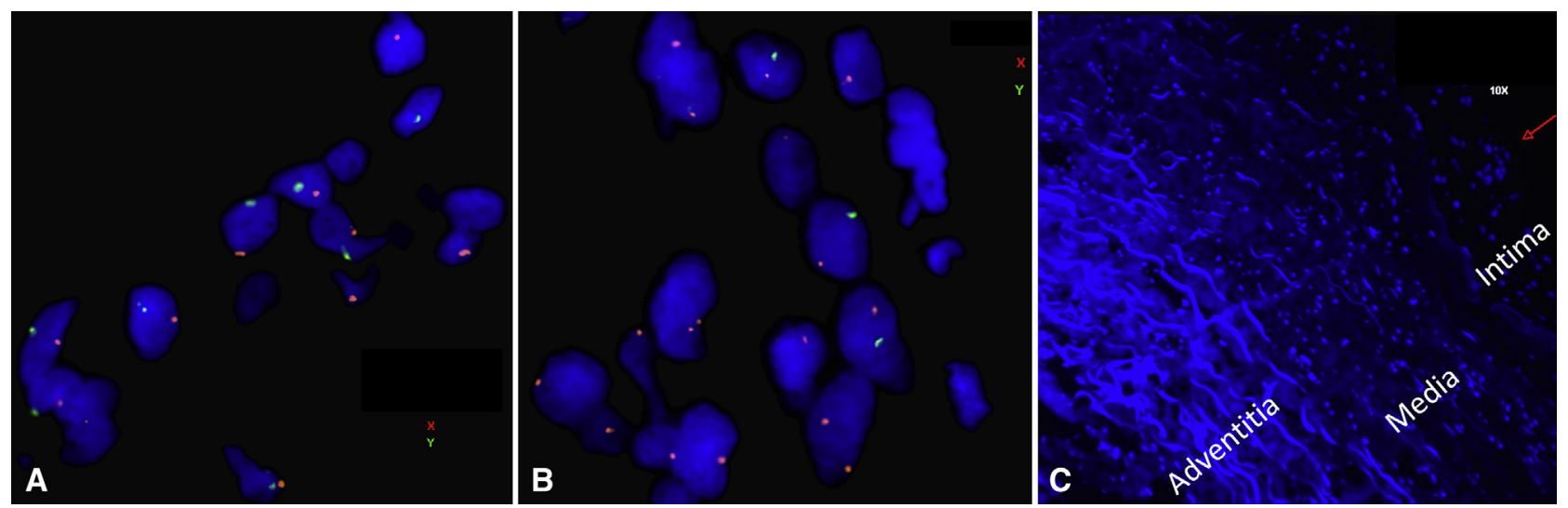

FIGURE 7. A, FISH analysis demonstrates all male cells (green and red signals) in the unimplanted valved venous homograft consistent with a male donor origin. B, Predominantly female cells (double red signal) of host origin with a few male cells ( green and red signals) of graft donor origin by FISH analysis in the thickened fibrointimal layer in one of the explanted grafts from a female recipient, consistent with tissue chimerism. C, Low-power view showing the location within an area of fibrointimal hyperplasia of cell in B (red arrow). FISH, Fluorescent in situ hybridization. 


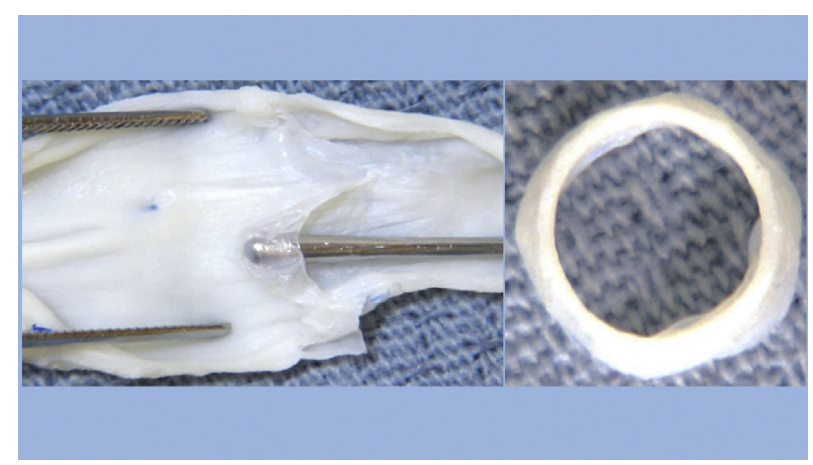

VIDEO 3. A summary of findings for valved venous homografts: Tissue changes and performance. Video available at: https://www.jtcvs.org/ article/S0022-5223(18)32497-8/fulltext.

the grafts, with patchy denuded areas. The presence of microthrombus lining some of these bare areas supports the protective capacity of the reformed endothelium. Endothelial coverage was extensive in the explanted grafts but virtually absent in the unimplanted segments, consistent with in situ proliferation, likely of recipient cells. ${ }^{9,10,20}$

The inflammatory response was unimpressive and rather similar to the typical mild mononuclear cell infiltrate observed microscopically in some other implanted biomaterials (eg, leaflets of bioprosthetic valves, pericardial heterograft). Although recipient humoral and cellular immune responses following cryopreserved homograft implantation have been described clinically by a number of investigators, ${ }^{21-25}$ the histopathologic correlate of these findings were quite inconsistent. ${ }^{16,26,27}$ Cell depopulation technique in addition to standard cryopreservation has recently been introduced and was shown to reduce antigenicity in pulmonary homograft used in vena caval reconstruction ${ }^{28,29}$; the potential benefit of this method in the processing of $\mathrm{VVH}$ for use as RV-to-PA conduits may be explored. Dystrophic calcification and foreign body giant cell reaction are usual tissue reactions to suture and other synthetic materials; these findings were confined to the anastomotic sites and did not involve the body of the graft. While the short duration in situ for many of the grafts limits our ability to assess longer-term potential for calcification, 4 to 6 months' duration is what is typically planned for a Sano shunt in univentricular hearts, so it is relevant for this use.

In our experience, most of the valves remained grossly intact and functional for up to almost a year, with only 2 of $20(10 \%)$ conduits exhibiting possible adhesion of the valves to the vein walls. We believe that the minimal inflammatory response observed in the valve leaflets, and the VVH in general, and limited fibrointimal hyperplasia of the leaflets allowed them to remain thin, pliant, and functional. Preservation of valve anatomy should make VVH amenable to balloon dilation if needed to increase pulmonary blood flow. In contrast, the VVH valves remained functional only in the first months in another series, with only one third remaining competent by the third month. ${ }^{10}$ It is unclear why there was such a difference between the 2 series. Histologic findings were not reported in that study.

On the basis of our findings in this small series, VVH appear to be suitable for use as RV-to-PA conduits in neonates and small infants. The venous homograft walls appear to undergo remodeling and thickening, which results in luminal narrowing in some cases and may be a limitation to the longevity of these small conduits. Angiographic stenosis was more frequent among female recipients. Externally stented VVH had a greater incidence of stenosis that tended to be more severe when compared with the nonstented ones, although the difference was not significant. There is minimal inflammation and calcification. The proliferating cells within the medial and intimal layers of the vein wall, which appear to drive the remodeling process, are predominantly of recipient origin. Equally important, the valves remained functional in the majority of conduits for up to 1 year (Video 3).

\section{Conflict of Interest Statement}

Dr Emani has received consultant fees from Cheisi Pharma. All other authors have nothing to disclose with regard to commercial support.

\section{References}

1. Pizzaro C, Norwood WI. Right ventricle to pulmonary artery conduit has a favorable impact on postoperative physiology after stage I Norwood: preliminary results. Eur J Cardiothorac Surg. 2003;23:991-5.

2. Pizarro C, Malec E, Maher KO, Januszewska K, Gidding SS, Murdison KA, et al. Right ventricle to pulmonary artery conduit improves outcome after stage I Norwood for hypoplastic left heart syndrome. Circulation. 2003;108(suppl 1):II155-60.

3. Rabinowitz EJ, Epstein S, Kohn N, Meyer DB. Promoting pulmonary arterial growth via right ventricle-to-pulmonary artery connection in children with pulmonary atresia, ventricular septal defect, and hypoplastic pulmonary arteries. World J Pediatr Congenit Heart Surg. 2017;8:564-9.

4. Shinkawa T, Chipman C, Bozzay T, Tang X, Gossett JM, Imamura M. Outcome of right ventricle to pulmonary artery conduit for biventricular repair. Ann Thorac Surg. 2015;99:1357-66.

5. Balasubramanya S, Zurakowski D, Borisuk M, Kaza AK, Emani SM, Del Nido PJ, et al. Right ventricular outflow tract reintervention after primary tetralogy of Fallot repair in neonates and young infants. J Thorac Cardiovasc Surg. 2018;155:726-34.

6. Forbess JM. Conduit selection for right ventricular outflow tract reconstruction: contemporary options and outcomes. Semin Thorac Cardiovasc Surg Pediatr Card Surg Ann. 2004; 7:115-24.

7. Reinhartz O, Reddy VM, Petrossian E, MacDonald M, Lamberti JJ, Roth SJ, et al. Homograft valved right ventricle to pulmonary artery conduit as a modification of the Norwood procedure. Circulation. 2006;114(1 suppl):I594-9.

8. Takeuchi K, Murakami A, Takaoka T, Takamoto S. Evaluation of valved saphenous vein homograft as right ventricle-pulmonary artery conduit in modified stage I Norwood operation. Interact Cardiovasc Thorac Surg. 2006;5:345-8.

9. Briceno-Medina M, Kumar TKS, Sathanandam S, Boston U, Perez M, Allen J, et al. Femoral vein homograft as Sano shunt results in improved pulmonary artery growth after Norwood operation. Cardiol Young. 2018;28:118-25.

10. Kumar TKS, Briceno-Medina M, Sathanandam S, Joshi VM, Knott-Craig CJ Femoral vein homograft as right ventricle to pulmonary artery conduit in stage 1 Norwood operation. Ann Thorac Surg. 2017;103:1969-74.

11. Schiller O, Sinha P, Zurakowski D, Jonas RA. Reconstruction of right ventricular outflow tract in neonates and infants using valved cryopreserved femoral vein homografts. J Thorac Cardiovasc Surg. 2014;147:874-9. 
12. Baird CW, Myers PO, Borisuk M, Pigula FA, Emani SM. Ring-reinforced Sano conduit at Norwood stage I reduces proximal conduit obstruction. Ann Thorac Surg. 2015;99:171-9.

13. Hoganson DM, Cigarroa CL, van den Bosch SJ, Sleeper LA, Callahan R, Friedman $\mathrm{KG}$, et al. Impact of a composite valved RV-PA graft following the stage 1 palliation. Ann Thorac Surg. June 30, 2018 [Epub ahead of print].

14. Motwani JG, Topol EJ. Aortocoronary saphenous vein graft disease: pathogenesis, predisposition, and prevention. Circulation. 1998;97:916-31.

15. Koolbergen DR, Hazekamp MG, Kurvers M, de Heer E, Cornelisse CJ, Huysmans HA, et al. Tissue chimerism in human cryopreserved homograft valve explants demonstrated by in situ hybridization. Ann Thorac Surg. 1998;66(6 suppl):S225-32.

16. Koolbergen DR, Hazekamp MG, de Heer E, Bruggemans EF, Huysmans HA, Dion RAE, et al. The pathology of fresh and cryopreserved homograft heart valves: an analysis of forty explanted homograft valves. J Thorac Cardiovasc Surg. 2002;124:689-97.

17. O'Brien MF, McGiffin DC, Stafford EG, Gardner MA, Pohlner PF, McLachlan GJ, et al. Allograft aortic valve replacement: long-term comparative clinical analysis of the viable cryopreserved and antibiotic 4 degrees C stored valves. J Card Surg. 1991;6(4 suppl):534-43.

18. Gavin JB, Barratt-Boyes BG, Hitchcock GC, Herdson PB. Histopathology of "fresh" human aortic valve allografts. Thorax. 1973;28:482-7.

19. Armiger LC, Gavin JB, Barratt-Boyes BG. Histological assessment of orthotopic aortic valve leaflet allografts; its role in selecting graft pre-treatment. Pathology. 1983;15:67-73.

20. Tam VK, Murphy K, Parks WJ, Raviele AA, Vincent RN, Strieper M, et al. Saphenous vein homograft: a superior conduit for the systemic arterial shunt in the Norwood operation. Ann Thorac Surg. 2001;71:1537-40.

21. Dignan R, O'Brien M, Hogan P, Thornton A, Fowler K, Byrne D, et al. Aortic valve allograft structural deterioration is associated with a subset of antibodies to human leukocyte antigens. J Heart Valve Dis. 2003;12:382-90.
22. Hawkins JA, Breinholt JP, Lambert LM, Fuller TC, Profaizer T, McGough EC et al. Class I and class II anti-HLA antibodies after implantation of cryopreserved allograft material in pediatric patients. J Thorac Cardiovasc Surg. 2000;119: 324-30.

23. Hawkins JA, Hillman ND, Lambert LM, Jones J, Di Russo GB, Profaizer T, et al. Immunogenicity of decellularized cryopreserved allografts in pediatric cardiac surgery: comparison with standard cryopreserved allografts. J Thorac Cardiovasc Surg. 2003;126:247-52.

24. Welters MJ, Oei FB, Witvliet MD, Vaessen LM, Cromme-Dijkhuis AH, Bogers AJ, et al. A broad and strong humoral immune response to donor HLA after implantation of cryopreserved human heart valve allografts. Hum Immunol. 2002;63:1019-25.

25. Oei FBS, Welters MJ, Vaessen LM, Stegmann AP, Bogers AJ, Weimar W. Induction of cytotoxic T lymphocytes with destructive potential after cardiac valve homograft implantation. J Heart Valve Dis. 2000;9:761-8.

26. Mitchell RN, Jonas RA, Schoen FJ. Pathology of explanted cryopreserved allograft heart valves: comparison with aortic valves from orthotopic heart transplants. J Thorac Cardiovasc Surg. 1998;115:118-27.

27. Rajani B, Mee RB, Ratliff NB. Evidence for rejection of homograft cardiac valves in infants. J Thorac Cardiovasc Surg. 1998;115:111-7.

28. Wells W, Malas M, Baker CJ, Quardt SM, Barr ML. Depopulated vena caval homograft: a new venous conduit. J Thorac Cardiovasc Surg. 2003;126:498-503.

29. Elkins RC, Lane MM, Capps SB, McCue C, Dawson PE. Humoral immune response to allograft valve tissue pretreated with an antigen reduction process. Semin Thorac Cardiovasc Surg. 2001;13(4 suppl 1):82-6.

Key Words: Valved venous homografts, composite Sano shunt, wall remodeling, neointima formation, flourescent in situ hybridization 


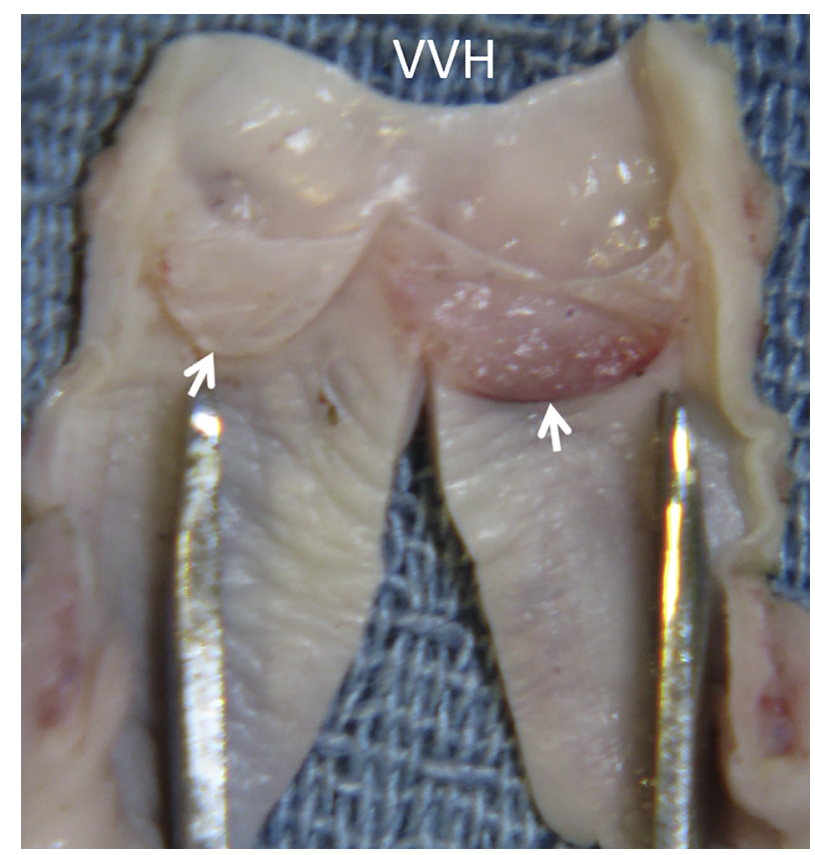

FIGURE E1. A femoral VVH implanted in a 2-ventricle heart without a Gore-Tex segment and without an external stent. The valves (arrows) are intact, and there is only mild wall thickening. The graft was in situ for 96 days. $V V H$, Valved venous homograft.

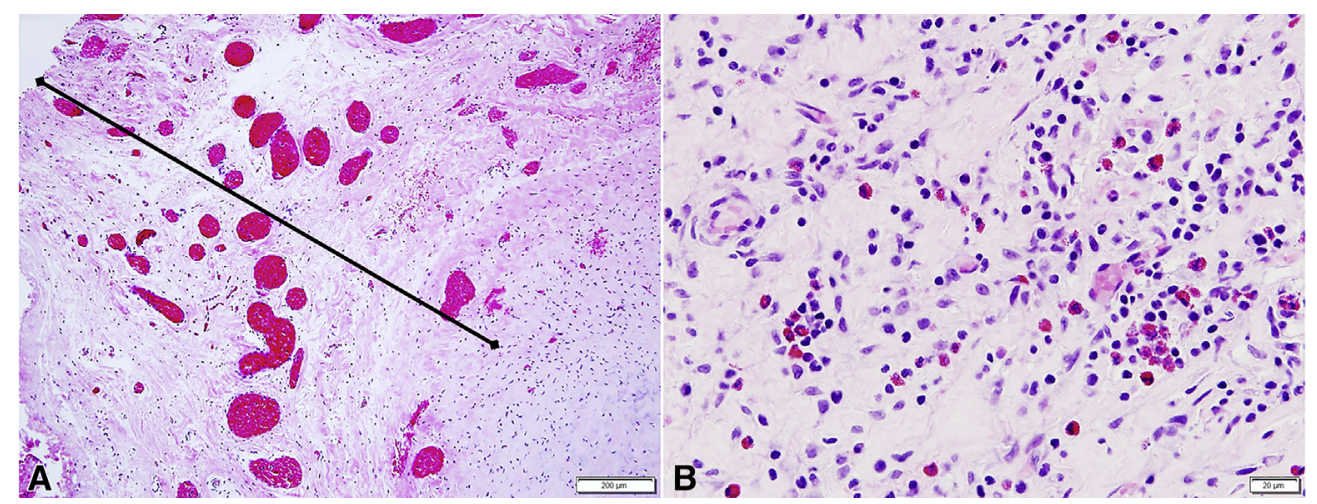

FIGURE E2. A, Femoral vein homograft explanted after 275 days showing a fibrotic adventitia (bar), with neovascularization. Few scattered inflammatory cells are present (hematoxylin and eosin, $10 \times$ ) (B) Saphenous vein homograft explanted after 96 days (hematoxylin and eosin, $60 \times$ ) showing mixed inflammatory cell infiltrate in the adventitia. Lymphocytes, plasma cells, and histiocytes are the usual cellular constituents. In 2 specimens, eosinophils were also noted. 


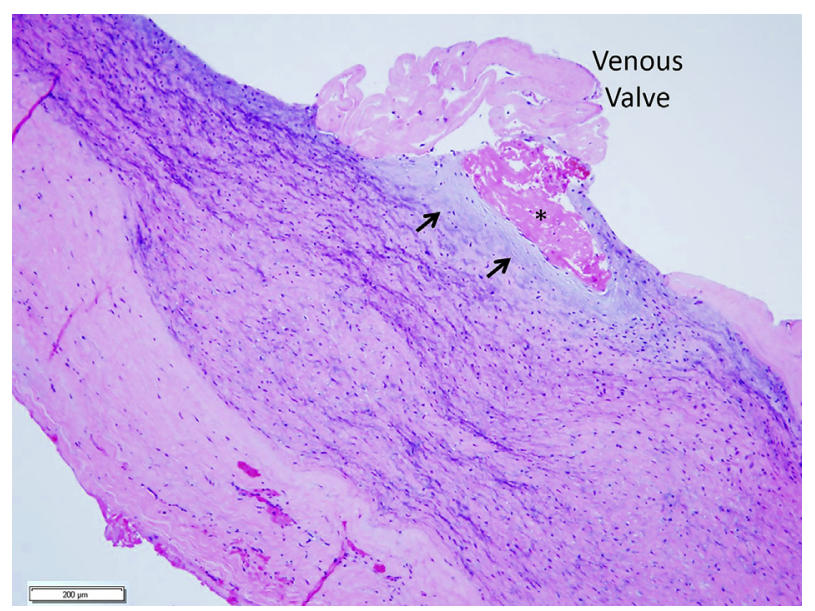

FIGURE E3. A microthrombus (*) is noted at the site in which the venous valve adjoins the valved venous homograft wall (hematoxylin and eosin, $10 \times)$. The arrows point toward the microthrombus.

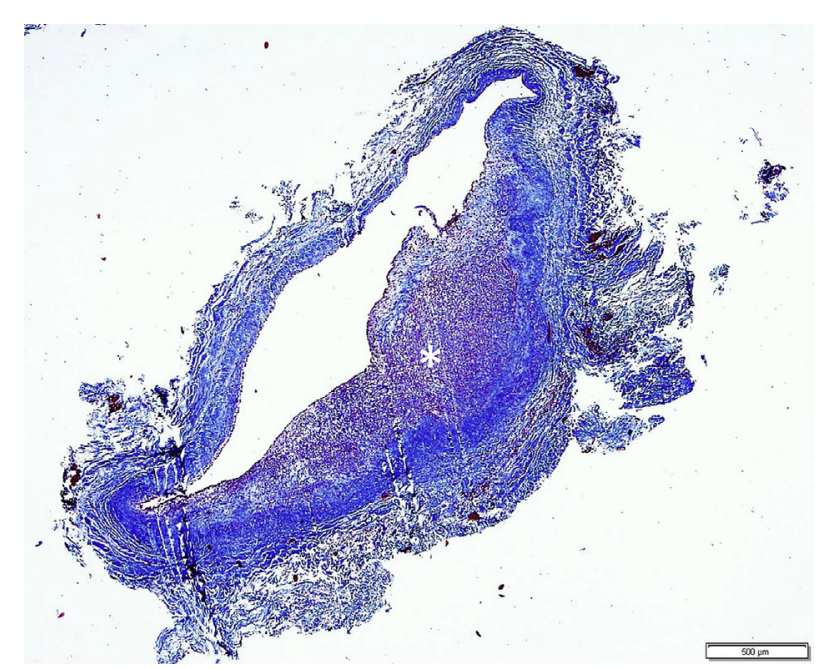

FIGURE E4. Fibrointimal hyperplasia in explanted valved venous homograft was variable and often focal as in this case, which shows marked thickening on the right side $(*)$ with the remainder of the wall being relatively normal (trichrome; $4 \times$ ). 

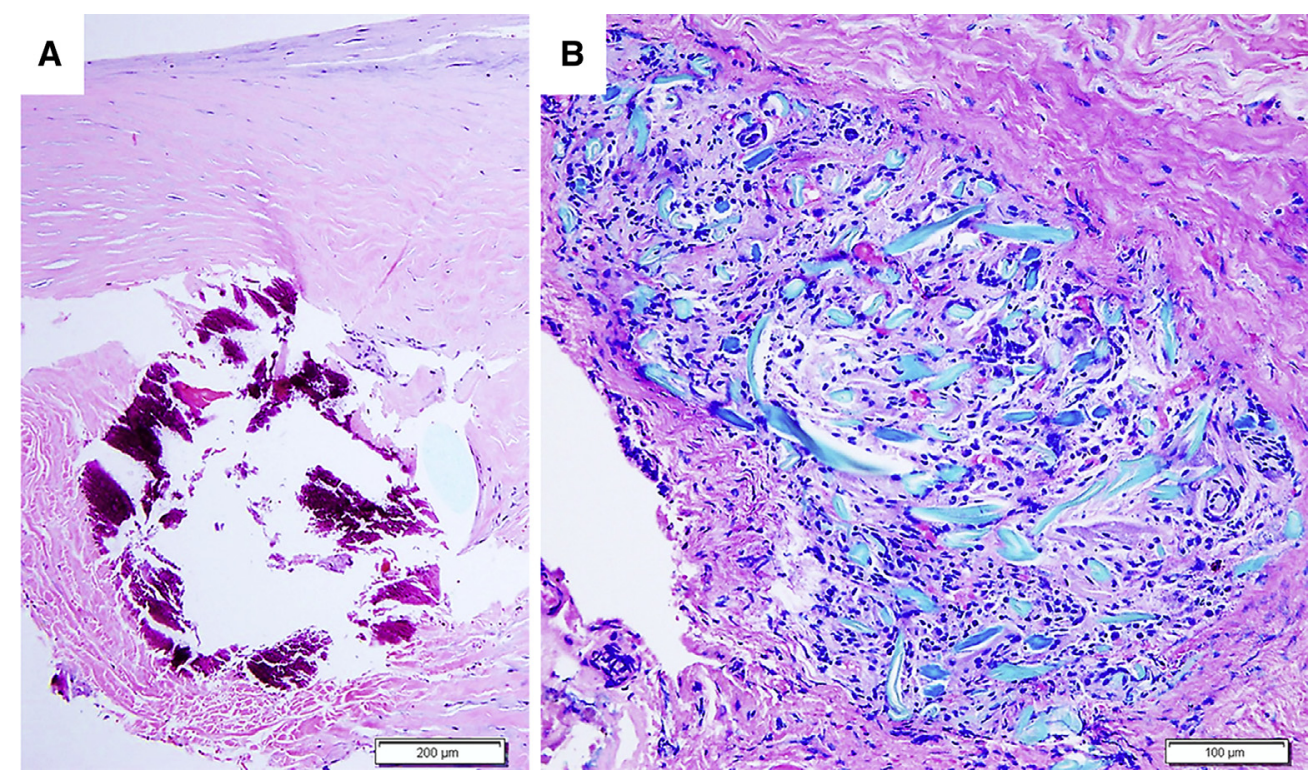

FIGURE E5. A, Calcification (purple) near suture material (hematoxylin and eosin, 10×). B, A collection of histiocytes with foreign body giant cell formation surrounding fragments of suture $(\mathrm{H} \& \mathrm{E}, 20 \times)$. 